\title{
Social costs and benefits of the universal service obligation in the postal market ${ }^{1}$
}

\author{
Helmuth Cremer ${ }^{2}$, Philippe De Donder ${ }^{3}$, \\ François Boldron ${ }^{4}$, Denis Joram ${ }^{5}$ and Bernard Roy ${ }^{6}$
}

May 2007

\footnotetext{
${ }^{1}$ Preliminary and incomplete. $\backslash$ Please do not quote or circulate.

${ }^{2}$ IDEI, University of Toulouse

${ }^{3}$ IDEI, University of Toulouse

${ }^{4}$ La Poste

${ }^{5}$ La Poste

${ }^{6}$ La Poste. The opinions expressed in this paper are those of the authors and do not necessarily reflect the positions of the Groupe La Poste.
} 


\section{Introduction}

The universal service obligation (USO) is a cornerstone of regulatory policy in the postal sector. In the EU, where the sector is headed towards full liberalization, the USO is the major argument used to advocate some residual regulation. In the postal sector, like in many other network industries, universal service was historically provided by a monopolistic public or regulated operator. While the need for monopoly protection has been increasingly disputed, the very idea of universal service has remained relatively uncontested during the early stages of the liberalization process. The debate was not that much about the appropriate extent of the USO but about the most efficient (or least costly) way to make it competitively neutral, or at least as compatible as possible with competition. This in itself is a challenging question.

More recently, however, the USO in itself has increasingly been questioned. The question is whether the social benefits associated with the USO are significant enough to justify its cost and in particular the impediment to competition it often implies. The spectacular development of electronic communications is likely to further fuel this debate.

To ensure a sound design of the future regulatory context in the postal sector, it is important not to restrict this debate to political or ideological considerations. The underlying economic aspects are of crucial importance and have to be given thorough consideration. While there are some papers in the literature that deal with this issue, it appears fair to say that most of the contributions on USO have concentrated on the "how" (to implement) rather than on the "why" (to impose it and to what extent). This is true to some extent for all network industries but even more so for the postal sector. ${ }^{7}$

This paper provides a detailed analysis of the benefits and costs of the USO in the postal sector.

\footnotetext{
${ }^{7}$ Exception are Cremer et al. (1997) and Cremer et al. (2001). Crew and Kleindorfer (1998) study the relationship between USO and reserved area under entry. Doing this they also discuss the nature of and justification for the USO.
} 
We present and assess alternative economic justifications of the USO. These include the idea that a USO may be used as a remedy for network externalities, that a USO is a form of redistributive pricing policy, that it can be a channel to supply a public good or an instrument of regional policy.

Amongst these, the redistributive pricing argument is probably the most unexpected one and needs some further elaboration. Prices are referred to as "redistributive" when they are not solely set according to (private or social) efficiency considerations. We argue that USO is first and foremost a constraint on pricing; the obligation to provide service without an affordable pricing requirement would be an empty constraint. We show that USO may be an optimal second best policy, and that this is true even within the sender pays context of the postal sector. We also identify the (social) costs of USO and suggest some avenues along which a formal cost benefit analysis of USO can be carried out.

Another aspect that will be explored is the role of the postal network as "intermediary" between firms and consumers (who interact through the "platform" provided by the postal network). This is related to the notion of network externality that has traditionally been used to justify the USO in telecommunications. However, the recent literature on two sided markets has taken a fresh look at these forms of interactions. Specifically, it has brought together the notions of usage and membership externalities and studied their implications on the pricing rules. One of the messages that has emerged from this literature is that "membership fees" on one side of the market may be below cost (or even negative). We shall examine if and to what extent the view of the postal network as a two sided market can provide a rationale for a USO.

Before proceeding it is useful to briefly review the definition of a USO. It involves the obligation of an operator to supply a specific package of goods and services, of a determined quality, to all users at "affordable" rates. In the European Union, a minimum definition is contained in the EU directives. It can be reinforced by individual member countries according to the principle of subsidiarity. In Germany or in France for instance, the requirement concerning the delivery frequency goes beyond the minimal EU requirements of 5 days a week. Similarly, uniformity of 
prices is not an obligation but just a possible option. Nevertheless, many Member States (including the UK, Denmark and France) have transposed in their law a uniformity obligation (for products within the scope of USO) rather than just an "affordability" requirement ${ }^{8}$.

Studying the rationale of USO involves two different questions. First, we can look for a justification of the USO on welfare grounds, taking into account the various constraints that the policy makers may face. Alternatively one can adopt a positive approach and explain why the USO is effectively imposed in most network industries. In this paper we focus on the first aspect while keeping the issue of political constraint in mind. We present a critical review of the major arguments that can justify a USO in the postal sector.

\section{Redistribution}

\section{Basic idea}

The USO can be seen as a special case of redistributive pricing, that is a policy meant to achieve redistribution through prices instead of (or in addition to) income taxation and/or "direct" transfers. This statement may come as a surprise and the reader may wonder why we refer to USO as a pricing policy and why we qualify it as redistributive. Consequently, two clarifying remarks are in order. First, one has to keep in mind the USO is primarily a constraint on pricing. The restrictions on pricing are a crucial ingredient in its definition. Without such a restriction, the obligation to provide service would be an empty constraint. An operator who can charge a price that is sufficiently large to cover cost has no reason to refuse the provision of service. Second, the term redistributive is used here to designate considerations that are not covered by efficiency. In other words, redistributive prices are prices that differ from those set on pure efficiency grounds (e.g., marginal cost driven).

Observe that a USO may imply two types of redistribution. First, towards high-cost customers

\footnotetext{
${ }^{8}$ See Ambrosini, Boldron and Roy (2005) for a description of the obligations in the different countries according to three dimensions: scope of products, quality requirements and price regulation.
} 
(e.g. single piece mail users) or adressees (e.g., mail sent to rural households). This is achieved through uniform pricing or whenever price differentials (between consumer groups) fall short of cost differentials. Second there may be redistribution towards low-income (or otherwise needy) individuals. Illustrations are social tariffs (in telecommunications or electricity). In the postal sector, the first aspect appears to be the most relevant. ${ }^{9}$ However, in reality, cost and income may be correlated : in France, low income people are more likely to live in rural areas. ${ }^{10}$ They benefit from universal service in two ways: first, as individuals senders, they benefit from the "affordable" redistributive price of the single-piece stamp, and second as addressees, they benefit from uniform pricing (see Section 3 below).

When viewed as redistributive pricing, a USO bears some similarities with policies involving "public provision of private goods" or in-kind transfers. The basic feature of these policies is that some essentially private goods like education, child care or health care are provided either free of charges or at (sometimes highly) subsidized prices.

\section{Economic background}

These policies can be justified in two ways. The first justification relies on the notion of specific egalitarism introduced by Tobin (1970). According to this view some goods are considered as essential in that they satisfy basic needs. Consequently, they ought to be made available to everyone irrespective of income, location or other considerations. This argument is often used to justify universal provision of health care or education but it can also apply to basic postal services. It is considered as debatable by many authors because it relies on the notion of paternalistic, non-Paretian preferences. Nevertheless it is a very popular view which typically draws a good deal of political support.

A more subtle (and less ad hoc) justification can be found in the public economics literature where it has been shown that such policies can be optimal in a second-best setting; that is when the policy makers do not have the necessary information to implement (potentially) more efficient policies like direct transfers. A detailed survey of this literature would go beyond the scope of this paper and we shall restrict ourselves to reviewing the arguments which are most

\footnotetext{
${ }^{9}$ This is true at least for mail services. Some financial services provided by post banks fall in the second category.

${ }^{10}$ See Roy (1999) for an analysis of cost drivers in postal delivery, and Bernard et al. (2001), for a comparison between France and USA, studying the costs of delivery rural areas and/or to low income households.
} 
relevant for the problem under investigation.

The gist of the argument is that the use of price subsidies makes it easier to target redistribution. Consider the case of health care. Provision at subsidized prices may create over-consumption and thus imply an inefficient outcome. Consequently, if the objective of the public authorities is to help the less-healthy individuals it would appear more efficient to do so directly, through a personalized transfer. Now, this is certainly true in a (hypothetical) world where public authorities can perfectly observe individual characteristics and can distinguish the needy from the well-off individuals. In reality, this is hardly the case and direct transfers to less-healthy individuals may be difficult to implement. Specifically, if sick individuals are entitled to some transfer, everyone has an incentive to pretend that he is needy and the verification of these claims would be impossible or very costly. However, if instead health care expenses are subsidized, the redistribution appears to be better targeted, even though it may come at the expense of some inefficiency (over-consumption).

To sum up, though potential generators of inefficiencies, price subsidies (or public provision at free or highly subsidized rates) may be an effective instrument of redistributive policies if alternative instruments (like personalized transfers) are not feasible for informational (or other) reasons. Observe also that political considerations may prevent direct transfers. This is most striking in the context of agricultural policy, but in the postal sector the replacement of USO by direct aid to rural residents may not be politically feasible either.

\section{Redistributing through USO in a sender-pays sector}

The view of the USO in the postal sector as a redistributive policy may give rise to two objections. First, in this sector, cost differentials arise mainly because of the locations (and types) of the addressees; the paying customers, on the other hand, are the senders. Second, the postal budget of a typical household is small and one can thus argue that the achieved redistribution is rather insignificant.

To establish that a USO can operate significant redistribution between, say, urban and rural individuals, it thus has to be shown that the eventual beneficiaries of the USO are not so much 
the senders, but rather the addressees, and specifically, the high-cost households. This claim is supported by at least three arguments.

First, the existence of cost differentials according to the location of the addressee is, to a certain extent, due to the USO. It is because operators face the obligation of delivering to the addressees' mailbox at a given frequency that rural delivery is more expensive. In the absence of a USO, reduced frequency, post office box delivery or similar measures could be implemented by the operator in order to eliminate the excess costs in rural delivery ${ }^{11}$. Such an adjustment would certainly have a much more significant impact on rural households than on the senders of the various mail items.

Second, in the absence of a USO, the postal operators could charge rural households for the delivery cost differentials by imposing a (periodic) fixed fee on those who opt for home delivery (rather then at some collective delivery point). In reality, such "connecting charges" do, of course, not exist in the postal sector (at least not in Europe), but this does not mean that the operators might not find such a pricing scheme optimal if the USO were removed. Now, the arguments which oppose such differential fees (and which may make them hard to accept on political grounds) are essentially of redistributive nature. From that perspective, the redistributive role of the USO is that it precludes certain (non linear) pricing schemes which would impose a heavier burden on high cost customers.

Third, most mail products are inputs rather then final goods. A large proportion of letters (and mail items in general) are sent by businesses, and economic analysis shows that firms generally manage to shift (at least part of) their costs to customers. Put differently, cost increases in postal items will, in general, lead to price increases for final goods or services, using mail as an input. Under uniform pricing in the postal sector, banks for instance, have no reason to charge rural customers more for the mailing of their bank statements than they charge their urban customers. However, if mailing costs were different, bank may find it profitable to differentiate fees according to the location of a customer. A similar argument goes through for many other types of

\footnotetext{
${ }^{11}$ See Boldron et al. (2006) for a study of the cost savings associated with a decrease in the number of routes.in rural areas.
} 
businesses and, in particular, for mail-order corporations. It is very likely that the burden of a removal of the uniform pricing requirement would eventually fall on the high-cost customers.

Consequently, the USO does effectively redistribute between high and low cost customers and the significance of this redistribution goes beyond the budget that rural customers directly spend on mail. The crucial point is that this redistribution is achieved indirectly because it concerns an input the cost of which will be reflected in the price of final goods. For example, the budget spent by each household (including small businesses) as a sender is about $68 €$ per annum in France. As an addressee, the average household receives a "mail budget" of $425 €$, that is more than six times the direct postal expenditures.. A formal model that illustrates and substantiates this argument is presented in Appendix A.

So far, we have focused on equity issues. We now examine if and how a USO can be justified on efficiency grounds.

\section{Network externalities and economic intermediation}

\section{Traditional view}

Network externalities are a classical justification of USO in telecommunications (see e.g. Riordan 2001). They arise when the benefits from using a network depend on the number of individuals who are connected to the network. Telecommunications provide a prominent example: the number of subscribers determines the number of individuals any particular user can communicate with. Consequently, any individual's decision to subscribe or not directly affects the utility of other individuals. However, when deciding upon participation, any particular consumer will only take his own (private) benefits into account. These externalities may lead to an inefficient outcome in an unregulated market and have an adverse effect on the development of the network. Specifically, one can expect participation rates to be too low. These inefficiencies may be reduced, through regulatory measures promoting the affordability of access to the network such as USO. From that perspective, USO can be seen as a device to correct market inefficiencies in the presence of network externalities. 
This traditional view relies on a symmetric view of externalities where all subscribers are potential callers and receivers. This view is probably of limited relevance for the postal sector.

\section{Externalities, intermediation and the two sided market approach}

A more modern approach to network externalities is provided by the "two-sided markets" framework. In this setting, a market is viewed as a platform (intermediary) for exchanges between agents on its two sides. The membership and/or usage on one side of the market affects the utility or profit opportunities on the other side. This gives rise to membership and/or usage externalities that are no longer symmetric. Take the prominent example of payment cards. The utility of a cardholder depends on the number of outlets that accept the card. Conversely the benefits of say a restaurant from accepting the card depends on the number of cardholders. These externalities affect pricing policies and in many circumstances it is desirable to "subsidize" membership or usage on one side of the market.

While the postal sector differs in several respects from the sectors that have been studied in the two-sided market literature, this view of externalities has interesting implications for the interpretation of a USO. ${ }^{12}$ The postal sector acts as an intermediary between firms and households. Firms' benefits from relying on postal products (as opposed to alternative media) depend on the number of households that can be reached (with a given quality of service). Conversely, households may benefit from the presence of a large number of firms. A USO can then be seen as a device to internalize these externalities. For instance, a direct application of two-sided market models to the case of pricing of usage and "membership" would show that making addressees pay for home delivery is not likely to be optimal. The free home delivery mentioned above for its redistributive merits could thus also be justified on efficiency grounds. We do not further pursue the issue of addressee's payments here since a fully-fledged study of postal sector pricing from a two-sided market perspective would go beyond the scope of this paper and is left for future research. ${ }^{13}$

\footnotetext{
${ }^{12}$ With the exception of Panzar (2006), who studies PO boxes, the two-sided market literature has to our knowledge not yet dealt with the postal sector.

${ }^{13}$ In any event, addressees' payments for delivery do not appear to be an issue for the time being, at least not in Europe. Note however that some types of delivery, such as to PO box, are not free and represent an interesting example of a receiver payment
} 
Instead, we use some ingredients of the two-sided market approach but focus on quality rather than pricing. In Appendix B, we consider a simple model where the benefits of senders depend on coverage of delivery network at a certain level of service (defined, for instance, by the number of deliveries per week). We also consider the possibility of a "call externality" according to which an addressee's utility depends on the number of mail items he receives. ${ }^{14}$ We show that a profit-maximizing (monopoly) operator can be expected to choose a degree of coverage that is too small. This means for instance that the part of the territory subject to six days a week delivery tends to be too small under profit maximizing behavior. The underlying problem is closely related to a choice of product quality (or quality of service) by a monopolistic firm.

This problem can be solved or at least mitigated through a USO. Under these circumstances USO thus appears to be justified on efficiency grounds. Specifically, it is efficiency enhancing when the profit-maximizing operator spontaneously sets a degree of coverage (a level of quality) that is too low.

This argument is likely to be reinforced if there is competition. In that case, the coverage of the incumbent may spill over to entrants' demands, which in turn increases surplus in that segment. A profit-maximizing operator has no reason to take this effect into account and an underprovision of quality is even more likely.

\section{Other arguments}

\section{Public/merit good}

It can be argued that a uniform and universal postal network presents the character of a "public good" because it "binds the nation together" or it is essential for the functioning of a democracy. The argument relies on the idea that the existence of the network is valuable in itself, independently of the specific services it provides to the consumers. Consequently, it may apply

(albeit on a membership rather than on a usage basis). 
even when the provided service is essentially a private good. From that perspective, a USO can be seen as a mechanism for the provision of this public good.

The importance of this aspect has been re-enforced in the recent Directive project launched by the Commission on October 2006. In this project, the accessibility of the postal network, (which is a component of universal service), is meant to promote social and territorial cohesion

\section{Regional policy}

The USO can also be an instrument of regional policies. For instance, uniform pricing can be a way to subsidize rural customers, in order to encourage households and firms to locate in rural areas (or to prevent them from moving away). Similarly, maintaining basic public services (like post offices) in small villages may contribute toward preventing the decline of rural areas. Many initiatives at the European level, such as the European Regional Development Fund or the European Spatial Development Perspective, pursue the objective of a balanced and sustainable spatial development. They are intended to achieve economic and social cohesion, to preserve cultural heritage, to manage natural resources and to obtain a more balanced competitiveness of the European territory ${ }^{15}$. Universal Services obligations in the postal sector can be seen as instruments to pursue these objectives.

\section{Conclusion}

We have presented two complementary perspectives on the benefits of USO. First, we have argued that a USO is a form of redistributive pricing that achieves redistribution between low cost and high cost consumers. We have shown that within the sender-pays framework adopted in the postal sector this redistribution is operated indirectly, through the firms that use postal products as inputs (and sell their final goods to households). Second, we have presented an argument that relies on externalities and intermediation to show that USO can also be justified on efficiency grounds. A delivery network with a large coverage and a high level of quality increases demand for postal products (specifically, for industrial mail products). A profit-

\footnotetext{
${ }^{14}$ Riordan (2001) considers such an externality for the telecommunications sector.

${ }^{15}$ See, Boldron et al.(2007) for more details on those policies
} 
maximizing operator does not appropriately account for this effect and sets a suboptimal level of coverage/quality. This effect is reinforced when there is a "call externality" (addressees obtain utility from receiving mail) and/or when there is competition.

The benefits associated with a USO come at a certain cost. On the one hand, there are the distortions to prices and competition and, on the other hand, there is the danger that quality is overprovided. For instance, it may not effectively be socially optimal to deliver six times per week on the entire territory for a given price.

The first category of costs depends on the design of the policy and, in particular, on the financing mechanism that is used. To avoid or mitigate the second type of costs, studies are necessary to ensure that appropriate standards are set.

What are the lessons we can learn from our analysis regarding the future role of the USO in a postal world of enhanced electronic communications? First or all, it appears that cancelling a USO and replacing it by (say) the provision of subsidized stamps to households is not a solution. This is because the relevant benefits of a USO are all related to the role of postal products as inputs and thus to the industrial mail segment. Furthermore, one can notice that the redistributive role of a USO is not directly related to the availability of Internet. These two points suggest that a USO does have a role to play in the future. However, we also have to keep in mind that all benefits considered depend on the demand for postal products and the role that the sector plays in economy. The crucial question that has to be asked is whether this channel of communication remains a crucial input for firms. 


\section{References}

Ambrosini, X., F. Boldron and B. Roy (2006), Universal service obligations in the postal sector: economic learnings from cross-country comparisons, in M.A. Crew and P.R Kleindorfer (eds), Progress towards Liberalization of the Postal and Delivery Sector, New York: Springer.

Bernard, S., R.H. Cohen, M.H. Robinson, B. Roy, J. Toledano, J.D Waller and S.S. Xenakis, (2002), Delivery cost heterogeneity and vulnerability, in M.A. Crew and P.R Kleindorfer (eds), Postal and Delivery Services: Delivering on Competition, Boston, MA: Kluwer Academic Publishers.

Boldron, F, K. Dewulf, D. Joram, C. Panet, B. Roy, and O. Vialaneix; (2007), The accessibility of the postal retail network and the objectives of social cohesion and economic development, to be presented at the $15^{\text {th }}$ Conference on Postal and Delivery Economics, Semmering, Austria.

Boldron, F., D. Joram, L. Martin, B. Roy, (2006), From the size of the box to the costs of universal service obligations: a cross-country comparison, in M.A. Crew and P.R Kleindorfer (eds), Liberalization of the Postal and Delivery Sector, Northampton, MA: Edward Elgar.

Cremer, H., M. De Rycke and A. Grimaud, (1997), Cost and benefits of universal service in the postal sector, in in M.A. Crew and P.R Kleindorfer (eds), Managing Change in the Postal and Delivery Industries, Boston: Kluwer Academic Publishers.

Cremer, H., F. Gasmi, A. Grimaud and J.J. Laffont, (2001), Universal service: an economics perspective, Annals of Public and Cooperative Economics, 72, 5-43.

Crew, M. and P. Kleindorfer, (1998), Efficient entry, monopoly and the universal service obligation in Postal Service, Journal of Regulatory Economics, 14, 103-125.

Crew, M. and P. Kleindorfer, (2007), Multi-national policies for the universal service obligation in the postal sector under entry, Review of Network Economics, forthcoming.

Julien, B., (2005), Two-sided markets and electronic intermediaries, CESifo Economic Studies, 51, 233-260.

Panzar, J. (2006), P0 Box Access: Competition Issues in a Two-Sided Postal Market, presented at the fourth conference on, Regulation competition and universal service in the postal sector, Toulouse, France. 
Riordan, M., (2001), Universal residential telephone service, in: Cave, M, S. Majumdar and I. Vogelsang (eds.), Handbook of Telecommunications Economics, Amsterdam Elsevier Science.

Rochet, J.C. and J. Tirole, (2007), Two-sided markets: a progress report, RAND Journal of Economics, forthcoming.

Roy, B., (1999), Technico-economic analysis of the costs of outside work in postal delivery, in M.A. Crew and P.R Kleindorfer (eds), Emerging competition in Postal and Delivery Services, Boston, MA: Kluwer Academic Publishers.

Tobin (1970), On limiting the domain of inequality, Journal of Law and Economics, Vol. 13, No. 2, 263-277.

Varian, H., (1987), Intermediate Microeconomics: A Modern Approach, WW Norton. 


\section{A. Redistributive pricing under the sender pays principle}

There are $N$ individuals and two areas indexed $u$ (urban) and $r$ (rural). The proportion of individuals living in the urban area is denoted by $\alpha$. The (constant) marginal delivery costs of one item of mail differ according to the location of the addressee and are given by $c^{u}<c^{r}$. All individuals consume some good $y$ (e.g., banking services) that use mail services as input. The production of one unit of $y$ requires one unit of mail. The cost of all other inputs required for producing a unit of $y$ is constant (and independent of location) and given by $k$. Let $p^{i}$ denote the prices paid by the producers of $y$ for mail sent to area $i=u, r$. The price of $y$ in area $i=u, r$ is denoted $q^{i}$. Assuming that $y$ is produced by a competitive industry, we have $q^{i}=p^{i}+k$. With this linear technology, the cost of the input is entirely shifted to the consumer. ${ }^{16}$ The indirect utility of a consumer located in area $i$ is given by $v\left(q^{i}\right)$ while demand for $y$ is denoted by $y\left(q^{i}\right)$; in other words, all other prices and incomes are considered as given (and mail is only used as input). ${ }^{17}$

The pricing problem of a (postal) regulator who cares for efficiency and redistribution can then be expressed as the maximization of a social welfare function subject to a break-even constraint:

$$
\begin{array}{ll}
\max _{p^{u}, p^{r}} & \alpha N \Psi\left[v\left(p^{u}+k\right)\right]+(1-\alpha) N \Psi\left[v\left(p^{r}+k\right)\right] \\
\text { s.t. } & \alpha N\left(p^{u}-c^{u}\right) y^{u}+(1-\alpha) N\left(p^{r}-c^{r}\right) y^{r}-F=0,
\end{array}
$$

where $F$ is the postal operator's fixed cost, $y^{i}=y\left(q^{i}\right), i=u, r$ and where $\Psi$ is an increasing and concave function. The degree of concavity reflects the importance of redistribution in the regulator's objective. For instance we can set

$$
\Psi=\frac{v^{1-\rho}}{1-\rho},
$$

with $\rho \geq 0$. For this specification $\rho=0$ yields a utilitarian welfare function, which with quasi-

\footnotetext{
${ }^{16}$ With more general technologies we would get partial shifting: an increase in $p$ of $\Delta$ would lead to an increase of $q$ of $\gamma \Delta$ with $0 \leq \gamma \leq 1$. This would complicate the analysis but our argument would remain valid.

${ }^{17}$ For simplicity we assume that preferences are quasi-linear so that utility and surplus are equivalent.
} 
linear preferences implies that there are no benefits associated with redistribution (social welfare is measured by total surplus). At the other extreme, $\rho \rightarrow \infty$ yields the Rawlsian welfare function: social welfare is measured by the utility of the worst-off individual. Observe that this problem illustrates the indirect redistribution argument presented in Section 2 above. The price of the input (mail products) affects the price of the final good bought by rural and urban consumers.

Differentiating the Lagrangian expression associated with this problem yields the following pricing rules

$$
\begin{aligned}
& \frac{p^{u}-c^{u}}{p^{u}}=\frac{\lambda-\Psi^{\prime}}{\varepsilon^{r}}, \\
& \frac{p^{r}-c^{r}}{p^{r}}=\frac{\lambda-\Psi_{r}^{\prime}}{\varepsilon^{r}},
\end{aligned}
$$

where $\varepsilon^{i}, i=u, r$ is the absolute value of demand elasticity while $\lambda$ is the multiplier of the break even constraint. To interpret these expressions, consider first the case where $F=0$. In that case, when $\Psi$ is linear $\left(\Psi^{\prime}=1 ; \rho=0\right)$ the solution implies marginal cost pricing and we have $c^{r}>p^{r} \geq p^{u}>c^{u}$ When $\Psi$ is strictly concave, we have $\Psi_{u}^{\prime}<\Psi_{r}^{\prime}$ yielding $p^{r}=c^{r}>p^{u}=c^{u}$. In other words, the price differential is smaller than the cost differential. In the Rawlsian case prices will be equal. Finally, when $F>0$, we have simple Ramsey pricing when $\Psi^{\prime}=1$ and this implies $p^{r}>p^{u}$ (unless $\varepsilon^{r}$ is much smaller than $\left.\varepsilon^{u}\right)^{18}$. Strict concavity of $\Psi$ continues to imply $\Psi_{u}^{\prime}<\Psi_{r}^{\prime}$ and the price differential will decrease with the degree of concavity. In the Rawlsian case prices will again be equal.

\section{B. Optimal vs. profit maximizing coverage}

Let $\mu$ denote the proportion of the $N$ addressees (the one with the lowest delivery costs) who can be reached through the postal network (with some specified quality of service like for instance, home delivery on a $D+1$ basis). The utility of the representative customer sending $x$

\footnotetext{
${ }^{18}$ The equation of the demand elasticity in both areas is the same, because utility functions are identical, but the
} 
units of mail at price $p$ to each addressee is given by ${ }^{19}$

$$
U S=N \mu v(x, \mu)-N \mu p x .
$$

Observe that $\mu$ plays two roles in this expression. It multiplies $v$ and $x$, which are defined on a per-addressee basis, to yield total utility and output. Furthermore, it is an argument of $v$ to capture the idea that the degree of coverage of the network is perceived by the sender as a quality attribute of mail.

We also introduce the possibility that receiving mail generates a "call externality". ${ }^{20}$ Each addressee's utility from receiving mail is given by $h(x)$ so that the sum of addressees' utilities is given by

$$
U A=N \mu h(x)
$$

The cost of the postal operator is specified by

$$
C=F(\mu)+N \mu c x,
$$

with $F^{\prime}>0$ and $F^{\prime \prime}>0$, so that profit is

$$
\pi=N \mu p x-F(\mu)-N \mu c x
$$

For simplicity we assume here that the marginal delivery cost does not depend on the addressee's location. However, the fixed cost of maintaining the network depends on location; this explains that $F$ is a strictly convex function of $\mu$.

\section{Socially optimal solution}

To determine the optimal solution $\left(x^{*}, \mu^{*}\right)$ we maximize a utilitarian welfare $W$ (equivalent here to total surplus). ${ }^{21}$ We have

$$
\begin{aligned}
W & =U S+U A+\pi \\
& =N \mu \nu(x, \mu)+N \mu h(x)-F(\mu)-N \mu c x .
\end{aligned}
$$

values taken at equilibrium will in general differ.

${ }^{19}$ This is a simplified version of the utility function used by Cremer et al. (2001).

${ }^{20}$ On this terminology, see Riordan (2001).

${ }^{21}$ For simplicity, we concentrate on the first-best solution and do not impose a break-even constraint on the operator. This does not affect the results pertaining to the determination of $\mu$. 
Differentiating with respect to $x$ and $\mu$ yields:

$$
\begin{aligned}
& \frac{\partial W}{\partial x}=\left[\frac{\partial v}{\partial x}+h^{\prime}(x)-c\right] \mu=0 \\
& \frac{\partial W}{\partial \mu}=N[v(x, \mu)+h(x)-c x]+N \mu \frac{\partial v}{\partial \mu}-F^{\prime}(\mu)=0 .
\end{aligned}
$$

The two conditions have straightforward interpretations. Equation (7) states that the marginal benefit of $x$ (accounting for the call externality $\left.h^{\prime}(x)\right)$ equals its marginal cost. Similarly, in (8) the first two terms measure the marginal benefit of an increase in $\mu$ while the last term represents the marginal cost.

\section{Profit-maximizing solution}

Writing profits as a function of $\mu$ and $x$ yields

$$
\pi=N \mu p(x, \mu) x-F(\mu)-N \mu c x,
$$

where $p(x, \mu)$ is the inverse demand function. Differentiating yields the following FOCs

$$
\begin{aligned}
& \frac{\partial \pi}{\partial x}=N \mu\left[x+\frac{\partial p}{\partial x}-c\right]=0 \\
& \frac{\partial \pi}{\partial \mu}=N \mu \frac{\partial p}{\partial \mu} x+N[p(x, \mu) x-c x]-F^{\prime}(\mu)=0
\end{aligned}
$$

Based on (7)-(8) and (9)-(10) the comparison between the social optimum $\left(x^{*}, \mu^{*}\right)$ and the profit maximizing solution $\left(x^{\pi}, \mu^{\pi}\right)$ is not entirely obvious. One easily shows that $x^{\pi}<x$, but the comparison between $\mu^{\pi}$ and $\mu^{*}$ is ambiguous. ${ }^{22}$

We can gain some further insight by noting that for any level of $x$, the derivative of $W$ with respect to $\mu$, at the profit maximizing level of $\mu$ is simply

$$
\frac{\partial W}{\partial \mu} W=\frac{\partial U S}{\partial \mu}+\frac{\partial U A}{\partial \mu}+\frac{\partial \pi}{\partial \mu}=\frac{\partial U S}{\partial \mu}+\frac{\partial U A}{\partial \mu},
$$

\footnotetext{
${ }^{22}$ This is similar to the problem of quality choice by a profit-maximizing monopoly; see Varian (1992) p. 239-241.
} 
because $\partial \pi \partial \mu$ vanishes by definition when profit is maximized. In words, profit maximization yields a level of coverage that is too low (given $x$ ) when consumer surplus (counting both the senders and the addressees) increases in $\mu$. It is plain from (4) that $\partial U A / \partial \mu>0$. Furthermore, we have

$$
\frac{\partial U S}{\partial \mu}=N[v(x, \mu)-p x]+N \mu\left[\frac{\partial v}{\partial \mu}-\frac{\partial p}{\partial \mu} x\right]
$$

This first term in this expression is positive. Intuitively, the quantity sold by a profit-maximizing monopolist is too small at both the intensive and the extensive margin and this term captures the extensive margin. The second term is the usual quality term the sign of which depend on the sign of $\partial p^{2}(x, \mu) / \partial x \partial \mu$; see Varian (1987). 